\title{
ANIROPOLOGIA E ESOTERISMO: DOIS CONTRADISCURSOS DA MODERNIDADE
}

\author{
José Jorge de Carvalho \\ Universidade de Brasília - Brasil
}

Resumo: Este ensaio visa analisar as complexas relações entre duas visões de mundo que se desenvolveram no mundo ocidental a partir da segunda metade do século vinte: o esoterismo e a Antropologia entendida como disciplina acadêmica. Procuro mostrar que ambas correntes de pensamento são ao mesmo tempo herdeiras do projeto da modernidade e críticas do seu sistema de valores. De fato, tanto a Antropologia como as tradições esotéricas se opõem ao modelo weberiano de racionalidade, reeditado nos nossos dias por Habermas, que visa separar, como se fossem autônomas, as esferas da ciência, da arte e da moral. Três conceitos importantes do esoterismo são discutidos à luz da abordagem antropológica: tradição, iniciação e ciência sagrada, o que conduz a uma proposta de reintegração dos saberes humanos sobre a experiência religiosa em suas mais diversas manifestações etnográficas.

Palavras-chave: antropologia, esoterismo, modernidade, racionalismo.

\begin{abstract}
This essay seeks to analyse the complex relationships between two worldviews that were developed in the West during the second half of the nineteenth century: esotericism and Anthropology as an academic discipline. I try to show that these two trends of thought are simultaneously heirs of the modernist project and critical of its basic system of values. In fact, Anthropology and esotericism are opposed to the Weberian model of rationality, defended nowadays by Habermas, which seeks to separate the spheres of science from those of morality and art, as if they were autonomous in relationship to each other. Three crucial concepts of esotericism are approached from an anthropological point of view: tradition, initiation and sacred science, which leads to a proposal of reintegrating human knowledge about religious experiences in their most diverse ethnographic manifestations.
\end{abstract}

Keywords: anthropology, esoterism, modernity, racionalism. 
Uma parte considerável do esforço dos teóricos das Ciências Sociais, principalmente em sua fase formativa ou clássica, foi colocado na tentativa de compreender como o mundo da modernidade se construiu sobre o arcabouço da racionalidade científica. Por outro lado - e complementar a essa investigação - não se pode praticamente isolar a construção teórica da modernidade dos estudos sobre a religião no Ocidente, levados a cabo também durante aquela mesma fase clássica. Auguste Comte fundou a ciência positiva da sociedade sobre as bases de uma crítica à vida religiosa; Emile Durkheim buscou compreender a vitalidade do vínculo social (o qual, pensava ele, ameaçava desfazer-se nas sociedades européias de sua época) postulando a efervescência da vida religiosa que detectava nos estudos sobre as sociedades pré-modemas. E Max Weber, ao fazer uso consistente da famosa expressão "o desencantamento do mundo" na sua avaliação da condição moderna, declarou o fim de um modelo de vínculo sagrado nas relações entre os homens e suas consequências para a consolidação da experiência individual do mundo do espírito.

De modo similar, uma parte significativa do pensamento filosófico e teológico do século XX compartilha dessa dilacerante avaliação weberiana. Num dos extremos estão aquelas correntes que assumem positivamente esse desencantamento, como se fosse ele mesmo o solo adequado, quer seja para a construção de qualquer alternativa aos valores e às promessas fundantes da postura moderna, quer para renunciar a esse projeto de reavaliação. Aqui podemos lembrar, por exemplo, o projeto radicalmente reativo e rebelde de um Michel Foucault, crítico acérrimo de todas as fontes de poder e por isso mesmo cético em relação a todos as propostas e promessas de emancipação, em especial as de cunho religioso. No outro extremo estão aquelas propostas, mensagens e tentativas de estruturação simbólica que pretendem reencantar o mundo aceito como decaído. Nessa linha estão os projetos, desenvolvidos de modo a serem compatíveis com a chamada modernidade reflexiva, conhecidos genericamente como diálogos inter-religiosos, tais como os de Raymundo Panikkar (1978) e o de Michael Amaladoss (1994).

O mundo acadêmico, espaço a partir do qual teço essas considerações, também partilha dessas alternativas do espírito contemporâneo, sobretudo pelo seu lado de negação. Um certo desencanto com a academia, por exemplo, é cada vez mais frequente, ainda que raramente expresso nos termos aqui apresentados. Propostas para reencantar a prática acadêmica, porém, raramente constam das pautas vigentes do que se concebe por pensamento 
contemporâneo. Uma das poucas exceções que posso citar é Josef Piper, que propôs um regresso aos valores da academia grega, visando recuperar sua dimensão iniciática, ociosa, criativa e sagrada. Numa ousadia rara para um filósofo contemporâneo, Piper (1983, p. 211), ao insistir na necessidade da hierarquia e do afastamento do mundo como constitutivos da academia, desafia: "resta o problema da relação entre o acadêmico e o esotérico, que é ainda mais ampla". ${ }^{1}$ Já uma resposta mais direta a uma leitura canônica da revelação do mundo trazida pela ciência pode ser encontrada na linha de estudos derivada de Gurdjieff e que encontrou suas expressões mais sistemáticas nas obras de Nicolas Ouspensky (1967) e Edward Nicoll (1957).

E na sociedade brasileira, como um todo, também subsistem, com maior ou menor grau de autoconsciência, representantes religiosos de toda essa gama de opções. Apenas muito recentemente vislumbramos a possibilidade de surgir uma terceira voz teórica, crescida justamente entre os subalternos, que nos restitua um olhar originário, capaz de identificar práticas religiosas em comunidades que não estão nem desencantadas nem em processo reflexivo de reencantamento. Adaptando para o caso específico da religião um argumento que desenvolvi a respeito da situação geral das tradições orais afro-americanas face às pressões provocadas pela expansão de uma cultura mediática transnacional, o olhar originário se refere à afirmação de que não somos periferia do espírito. Muito pelo contrário, as reflexões deste ensaio se baseiam na consciência de que a dimensão espiritual é intensa no Brasil e penso que seria mais apropriado argumentar, para o nosso caso, no sentido oposto da hipótese da secularização, derivada da idéia do mundo desencantado: o espaço da experiência religiosa só tem se intensificado em nossa parte do mundo ao longo do presente século. Um dos fatores que contribuiu para essa intensidade foi justamente a presença, entre nós, do universo esotérico.

Dentro desse contexto, para o qual fluem como relevantes o próprio devir histórico da Antropologia, a modernidade ocidental como projeto, o declínio da religião como "sentido primeiro e fundamental" (Vaz, 1980) e, sobretudo, a dimensão espiritual na sociedade brasileira contemporânea, é que me interessa investigar uma corrente de pensamento e espiritualidade que surgiu

\footnotetext{
1 O grande ensaio de Piper (1983) sobre o tema em discussão é O Ócio e a Vida Intelectual. De minha parte, já defendi a dimensão de encantamento inerente à prática antropológica em dois ensaios (Carvalho, 1988, 1993).
} 
também como uma reação muito particular à modernidade e suas conquistas materiais e filosóficas: o desenvolvimento das tradições esotéricas. Apesar das tradições esotéricas terem existido sempre como um contrapeso ao lado oficial, público, ou exotérico das religiões (modo de pensar e sentir que pode remontar à religiosidade do mundo antigo, baseada nas práticas de iniciação nos mistérios), há um tipo particular de esoterismo que passou a ser construído no Ocidente sobretudo a partir do século XVII, que se expandiu durante o apogeu do iluminismo e que veio a culminar com os grandes movimentos orientalizantes e espiritualistas da segunda metade do século XIX. Aí pontificaram, entre outros movimentos, os vários grupos de magos e escolas iniciáticas que se multiplicaram em número de adeptos e diversidade de propostas na França e a criação, na mesma época, da Sociedade Teosófica, ligada à figura extraordinária de Helena Petrovna Blavatsky, personagem com o qual se relacionam quase obrigatoriamente a grande maioria dos movimentos esotéricos existentes até os dias de hoje.

Esse grande movimento - espiritual, religioso, intelectual - que denomino aqui de esoterismo, poderia ser definido, em meus próprios termos, como a busca do sentido arcano, transcendente e da experiência iniciática, individual e plena, na era do mundo exaurido dos mistérios doutrinais e da caução sagrada do mundo; isto é, no caso do esoterismo moderno, na era do descrédito e da crítica à religião oficial e da ascensão definitiva da ciência como fonte primordial de saber e gnose. Esclarecendo um pouco mais, pode-se dizer que o esoterismo moderno dá continuidade, dialética e conscientemente, a vários outros movimentos de fundo iniciático e complementares ou confrontados com o cristianismo dominante, que existiram antes no mundo Ocidental. Dentre eles se destacaram: a fusão da Cabala judaica com o cristianismo, característica da época renascentista e que recebeu o nome genérico de Cabala Cristã; ${ }^{2}$ a tradição hermética, também tida como uma síntese da tradição cristã com tradições egípcias, gregas e romanas e fixada sobretudo nos tratados de Hermes Trismegisto conhecidos como o Corpus Hermeticum, livro que foi reintroduzido no mundo moderno por Marsilio Ficino na corte dos Médici de Florença; ${ }^{3}$ a Ordem Rosacruz, surgida em 1612, e que foi provavelmente o

\footnotetext{
Para um estudo crítico e histórico da Cabala Cristã ver a coletânea Kabbalistes Chrétiens (Hall, 1979).

Sobre a história de Hermes Trismegisto e o Corpus Hermeticum, ver a coletânea Présence d'Hermés Trismégiste (Piper, 1988); uma tradução recente dos tratados, com excelente aparato crítico, é a de Brian Copenhaver (1992).
} 
primeiro de todos esses movimentos místicos a adotar uma estrutura organizacional com intenções também nitidamente políticas; ${ }^{4}$ a tradição alquímica, viva por mais de dois mil anos e que declinou justamente nos primórdios da era iluminista, simultaneamente à consolidação do espírito científico moderno (Isaac Newton, um dos gigantes da formulação do método experimental na investigação da natureza, dedicou-se às práticas alquímicas durante os anos cruciais de suas descobertas e pode ser chamado, com propriedade, de último dos alquimistas). ${ }^{5}$ Uma das últimas influências, decisiva para a conformação do esoterismo moderno, foi o crescimento do interesse pelas religiões orientais, sobretudo pelas da índia, (basicamente hinduísmo e budismo) a partir das primeiras décadas do século XIX. ${ }^{6}$

Lembremos aqui que as disciplinas acadêmicas antecessoras da moderna Antropologia da Religião (História das Religiões, Religiões Comparadas) surgiram igualmente no mesmo período de expansão dos movimentos esotéricos de influência, oriental. Esse intercâmbio entre as duas respostas à racionalidade moderna só tem crescido nos últimos cento e cinquenta anos, a ponto de que as manifestações mais importantes do esoterismo contemporâneo são cada vez mais enriquecidas pelo material de pesquisa produzido pelos acadêmicos (antropólogos e historiadores da religião). E na mesma medida, todos os grandes mestres das Religiões Comparadas da segunda metade do século vinte - Mircea Eliade, Henry Corbin, Gilbert Durand, Seyyed Hosseín Nasr, Antoine Faivre, Jacob Needleman, entre outros - estiveram e estão todos em íntimo contato com a literatura esotérica.

Conforme argumenta Edward Tiryakian (1974), em um conhecido ensaio sociológico sobre o tema, o movimento esotérico se coloca como uma forma de crítica constante às propostas da modernidade religiosa, mística ou espiritual, em qualquer época da história. Sempre que surge uma onda de inovação de idéias, estas se difundem, se popularizam ou se vulgarizam e tendem, num certo momento, a se expandirem unicamente no nível horizontal - em outras palavras, se apresentam com a sua face exclusivamente exotérica;

4 Sobre a origem e o significado da tradição rosacruz, um estudo satisfatório é ainda o de Frances Yates (1978).

5 Sobre a trajetória alquimista de Newton, ver o estudo de Betty Jo Dobbs (1975); sobre a cosmovisão alquímica na sua fase clássica, pós-renascentista, ver meu estudo (Carvalho, 1995).

6 A maior autoridade contemporânea, tanto na história como na sistematização doutrinal do esoterismo ocidental é, a meu ver, Antoine Faivre; ver seu ensaio seminal (Faivre, 1994) e a coletânea por ele organizada em companhia de Jacob Needleman (Faivre; Needleman, 1995). 
aí a dimensão esotérica é mobilizada para que seja de novo tomada em conta a sua dimensão vertical, do espírito vivo.

Minha intenção é precisar certas coincidências, simultaneidades e equivalências entre o surgimento do esoterismo e outras correntes de idéias do século XIX. Tomando como referência básica a proposta teosófica de H. P. Blavatsky, pode-se avaliar em que medida ela ajudou a construir uma crítica radical ao declínio das tradições mitológicas e religiosas, uma retomada da utopia de uma vida humana mais harmônica, mais esclarecida e consciente, dentro de um quadro evolucionista que a aproxima, enquanto estrutura de pensamento, aos grandes esquemas evolucionistas e reformadores de Karl Marx, Herbert Spencer, Auguste Comte, Sigmund Freud, Edward Tylor e James Frazer. Para ficar no campo da disciplina antropológica, ouso afirmar que o projeto de construção de uma obra monumental, capaz de apresentar-se como síntese das diversas tradições religiosas do mundo, levado a cabo por Blavatsky em Isis sem Véu e n’A Doutrina Secreta, poderia ser comparado ao projeto d'O Ramo de Ouro, de James Frazer. Enquanto a mística russa punha em palavras um conhecimento tido como adquirido iniciaticamente (quer dizer, esotérico), o acadêmico inglês pretendia encarnar o espírito racional e transparente da disciplina científica oferecendo comparações formais de tradições, costumes, mitos e práticas rituais.

Após Blavatsky, e as várias dissidências e ramificações do esoterismo de cunho teosófico, outros pensadores formularam, em termos diversos, seus ideais esotéricos e suas críticas à modernidade. Destaco outros três nomes de grande influência, em seus dias e ainda nos dias de hoje: Julius Evola, autor do célebre $A$ Revolta contra o Mundo Moderno, René Guénon, autor de obras influentes como A Crise do Mundo Moderno e O Reino da Quantidade e os Sinais dos Tempos; e Fulcanelli, que fez os fascinantes estudos da tradição cristã medieval plasmados n' O Mistério das Catedrais e n’ As Moradas Filosofais.

De todas essas obras (e de muitas outras com elas parecidas) ressalta uma forma muito definida de criticar e responder à crise cultural e espiritual do mundo moderno. Há, por um lado, uma grande luta contra a perda do mistério, contra a interpretação supostamente rasante e exteriorizante que a ciência propõe do mundo. Se pensamos nas obras de Fulcanelli acima citadas, podemos contrastá-las, por exemplo, com o famoso ensaio de Erwin Panofsky sobre a arquitetura gótica e o pensamento escolástico: enquanto Panofsky se atém 
estritamente aos limites da disciplina acadêmica da iconografia, Fulcanelli também oferece o mesmo tipo de conhecimento sistemático sobre a arquitetura das catedrais, propondo porém uma forma distinta de relacionar-se com esse conhecimento, o qual deve remeter o leitor a um treinamento iniciático.

Outro aspecto sobressalente dessa postura esotérica é o ataque veemente a uma democratização do saber tida como falsa, o que torna esses autores pares de um Ortega y Gasset, por exemplo, cujo ensaio A Rebelião das Massas manifestava um duro repúdio à massificação do homem no início do século XX. Muitos deles assumem um perfil político nitidamente conservador. Julius Evola, por exemplo, n'A Revolta contra o Mundo Moderno, defende a existência de uma aristocracia que esteja preparada para controlar a disseminação social dos conhecimentos e poderes humanos tidos como mais sutis e profundos. Sobretudo em Evola, Guénon, Coomaraswami e Fulcanelli, defende-se a estrutura medieval das guildas, que fazia de cada aprendizagem de uma profissão uma iniciação nos mistérios herméticos. Assim entendida, essa defesa se soma à crítica marxista (entre outras) à alienação do trabalhador sob o regime capitalista. Por outro lado, esses autores fazem a apologia da rígida relação mestre versus aprendiz, duramente atacada pela ideologia igualitária do individualismo moderno.

Resumindo, pode-se dizer que o esoterismo mantém uma relação tensa (e talvez complementar) com a visão de mundo surgida na modernidade: procura apoiar-se nas ciências, ao mesmo tempo que critica uma cegueira da ciência institucionalizada. Algumas de suas correntes, mais voltadas para uma discussão do poder terrenal, chegam a defender uma hierarquia do saber contra o igualitarismo moderno. Outras, propensas a uma teoria da conspiração, criticam os grandes grupos econômicos e políticos (por exemplo, os banqueiros judeus sionistas, o Vaticano, as grandes corporações multinacionais, etc.) os quais, acreditam, comandam secretamente os destinos do mundo. Contra esse controle maléfico da humanidade, discutem as possibilidades de uma cavalaria espiritual e da construção de um contrapoder voltado para o bem e para o aprimoramento espiritual da espécie humana. ${ }^{7}$ Por outro lado, assim como a religião oficial e a tradição acadêmica institucionalizada que tanto critica, o esoterismo vive na pele a contradição de ser vítima de sua própria crítica:

7 Ver, por exemplo, a história do movimento conhecido como Sinarquia, proposta pelo famoso ocultista francês Saint Yves d’Alveydre, no livro de Jean Saunier (1979). 
esse utilitarismo, tão rejeitado, produto do odioso "reino da quantidade" (para utilizar uma expressão conhecida de René Guénon, um dos máximos expoentes do esoterismo no século vinte), está sempre rondando as seitas esotéricas, que muitas vezes transformam o seu saber iniciático em fórmulas quase objetivas e pragmáticas de controle e poder (segundo acusações vindas de dentro das próprias seitas).

Se tomamos essa plêiade de seitas e movimentos esotéricos existindo hoje em dia no Brasil, é possível observar que quase todos mantêm alguns traços comuns entre si, desenvolvidos a partir sobretudo da Teosofia e do Espiritismo, e nesse sentido é possível falar de uma gramática dos princípios esotéricos, que é o que buscarei fazer, na tentativa de compreender o movimento a nível macroscópico. De Blavatsky, Annie Besant, Krishnamurti, René Guénon, Julius Evola, Henrique José de Souza, Rudolf Steiner, Gurdjieff, Ouspenski, Serge Reynaud de la Ferriére, Mebes a Swami Prabhupada ou Rajneesh, sempre se trata de recolocar a experiência - física, intelectual e espiritual - prometida pelos textos canônicos e pela transmissão oral, de todas as grandes tradições espirituais da humanidade: hermetismo, alquimia, vedanta, cabala, gnose, budismo, astrologia, sufismo, etc., etc. Nesse sentido, cada movimento esotérico (e isso é progressivo, sendo ainda mais verdadeiro na atualidade) apresenta sua síntese particular das tradições universais. É tarefa do adepto refazer esse círculo a um nível mais estreito, fazendo seu, pessoal e intransferível, esse arcabouço de verdade universal sintetizado pelo seu mestre ou pelo fundador do seu grupo.

A imagem do fim de um mundo, trabalhada por René Guénon em $O$ Reino da Quantidade e os Sinais dos Tempos, pode ser vista como equivalente, nos textos de um continuador da proposta modernista como Jurgen Habermas, do alerta contra o perigo de que a razão instrumental conquiste de uma vez por todas o mundo da vida. Reino da quantidade e razão instrumental, independente dos horizontes argumentativos específicos de onde surgiram, podem ser considerados conceitos equivalentes. Essa mesma imagem guenoniana soaria igualmente familiar para os leitores de Martin Heidegger, sobretudo de seus ensaios Ciência e Meditação e Discurso sobre o Pensamento, em que ele discute a sobrevivência do pensamento meditativo contra os assaltos do pensamento calculante. A sensibilidade de Guénon seria assim do mesmo tipo da de Heidegger, tal como George Steiner a definiu em seu ensaio sobre o filósofo alemão: tratar-se-ia da visão de mundo regressiva 
dos conservadores. Steiner a coloca na mesma linha da nostalgia pastoral de Rousseau, contra a separação das funções éticas e estéticas, o que dá no mesmo que insistir no regresso à união entre arte e artesanato, tema enfatizado repetidas vezes por esotéricos do peso de Coomaraswami (1983), Titus Burckhardt (1958), Hossein Nasr (1992). ${ }^{8}$

Ao tentar mapear o universo esotérico no Brasil poderá revelarse interessante, do ponto de vista sociológico, analisar a frequência e as características das rupturas e dissidências entre as seitas. Valeria a pena verificar se os esquemas de segmentação são parecidos aos que ocorrem em outros países do mundo ocidental e também se se assemelham aos mecanismos de expansão das seitas protestantes, do espiritismo e das religiões afrobrasileiras, ou se são de um. tipo diverso.

De um ponto de vista teórico, penso que uma compreensão do mundo esotérico pode vir a corrigir, ampliar ou mesmo desfazer certas interpretações que se tem feito sobre a crise da religião na modernidade. Autores como Marcel Gauchet (1985) e Henrique de Lima Vaz (1992), por exemplo, ao discutir a crise simbólica do cristianismo a partir da visão hegeliana da morte de Deus, colocam com propriedade a centralidade da religião como transmissora do Sentido transcendente e sua crítica se move na direção de detectar a presença ou não desse Sentido unificador no mundo contemporâneo, dominado pela cultura de massa e pela razão instrumental. Todavia, nenhum deles coloca a presença do esoterismo como uma possível alternativa ou mesmo um questionamento desse suposto desaparecimento do Sentido transcendente. Minha hipótese, no momento, é de que esse Sentido, enquanto entendido como estável, constante, todo-abrangente, está associado à tradição simbólica da religião em seu lado socialmente exotérico, oficial ou institucionalizado. Para ficar exclusivamente com o cristianismo, Jacob Needleman (1987) comenta, em seu ensaio Cristianismo Perdido, como o lado esotérico, iniciático, do cristianismo, tão forte nos primeiros séculos da tradição, retrocedeu vertiginosamente no nosso século, permanecendo ainda vivo apenas em alguns setores da Igreja ortodoxa. ${ }^{9}$

8 Ver Steiner (1978).

9 Essa carência da dimensão mística, ou esotérica, do catolicismo, é lamentada por Frei Beto em seus comentários ao meu ensaio (Carvalho, 1994a). 
Por outro lado, o esoterismo recolocou com grande veemência (e a trajetória de H. P. Blavatsky é em tudo paradigmática desse movimento) a simbólica da busca, da demanda do Graal (da antiga à moderna, da literal-histórica à alegórica-atual); a trajetória iniciática; o desenvolvimento das faculdades superiores; o crescimento espiritual, etc. E esta simbólica em boa medida vem a ser complementar, contemporânea, de toda a simbólica de abertura e expansão que tanto caracteriza a modernidade em suas dimensões política, científica, estética e moral. Há ressonâncias, inclusive, desse clima esotérico, numa tradição intelectual (e também espiritual, para alguns) absolutamente típica da modernidade: a Psicanálise. A Psicologia Analítica de Carl G. Jung, por exemplo, compartilha explicitamente de uma boa parte dessa simbólica esotérica, sobretudo com as noções de individuação e de crescimento, que muitas equivalências quer guardar com o processo iniciático. Isso sem contar certas conexões mais evidentes, como a sua autoria heterônima e misteriosa dos Sete Sermões aos Mortos (apresentados anonimamente como uma psicografia de um tratado gnóstico, na linha dos textos alexandrinos de Valentim e Basílides), seus ensaios sobre mística e religião oriental e a própria natureza da sua autobiografia, Memórias, Sonhos e Reflexões, que se coloca na linha dos escritos dos grandes adeptos. ${ }^{10}$

No caso específico do Brasil, o campo religioso tem sido mapeado pelos estudiosos, definindo como linhas principais as seguintes: o catolicismo popular, a igreja católica institucionalizada, as seitas protestantes, o espiritismo, as diversas tradições religiosas afro-brasileiras e, em menor escala de importância etnográfica, as novas seitas, incluindo as de origem oriental e as que podem ser agrupadas sob o rótulo de Nova Era. Do mesmo modo que é possível defender que a influência de qualquer um desses segmentos da religiosidade brasileira transcende em muito o seu número formal de adeptos e participantes, pode-se sustentar que o universo esotérico permeia também a religiosidade do país muito mais do que a quantidade de seitas e participantes, ainda que já bastante vasta, pareceria indicar. Em princípio, parece-me que o lugar que o esoterismo ocupa relaciona-se em não pouca medida com uma certa oportunidade hermenêutica que oferece ao homem comum, roubado (sobretudo numa sociedade de baixa escolaridade) da capacidade de intervir mais

10 Ver o fascinante texto dos Septem Sermones ad Mortuos como apêndice da sua autobiografia (Jung, 1990). 
criativamente nos dois grandes universos conceituais que definem a nossa civilização: a tradição científica (ou, se se quiser, acadêmica) e a tradição cristã, ambas veiculadas através de seus representantes competentes: os cientistas, ou acadêmicos e os líderes religiosos (padres, pastores, etc.). Nesses dois universos, o controle pelo significado - e também pelo discurso legítimo - é extremamente severo e ambos se constróem como detentores da verdade fundamental e da reta conduta. É nesse sentido que uma das atividades típicas de um esotérico é fazer exercícios de análise simbólica, interpretando mitos ou fragmentos de mitos, decifrando esquemas simbólicos, fazendo elucubrações de caráter filológico, descobrindo analogias, conexões ocultas, etc. Toda essa atividade inclui também uma outra dimensão que é fundamental para compreender o fascínio do esotérico: a capacidade de fazer essas conexões e exegeses simbólicas refletirem diretamente na experiência pessoal.

Assim entendida, a presença da dimensão do esotérico, mesmo que em versões às vezes de fato fragmentadas, é muito alta em vários segmentos da sociedade brasileira. Seria útil pensar o esotérico como um outro tipo social, no sentido que Georg Simmel deu a certos tipos sociais em seus criativos ensaios do início do século. Aqui, o indivíduo esotérico conformaria um tipo singular de sensibilidade religiosa. Pois já podemos de certo modo circunscrever as sensibilidades específicas dos seguidores das outras vertentes religiosas hegemônicas no Brasil, tais como a dos católicos, dos protestantes, dos adeptos dos cultos afro-brasileiros e dos espíritas. O esotérico se caracterizaria então por um excessivo cuidado com o que se diz, a certeza de uma cumplicidade nas conversações sobre coisas do espírito, o pacto de silêncio rigoroso com os membros do grupo a que pertence, um estado constante de alerta diante de sinais tênues e às vezes recônditos de significados ocultos e reveladores. Aqui poder-se-ia enfatizar uma alta predisposição aos efeitos da sincronicidade e uma rejeição radical à obra do acaso. Seria igualmente interessante contrastá-lo com a figura do flâneur teorizada por Walter Benjamin; enquanto este circulava à deriva pelas galerias da grande metrópole do fim do século dezenove, aberto às vivências que lhe eram apresentadas pelas mercadorias profanas cintilando nas vitrines dos grandes magazines, o esotérico típico procurava decifrar signos sagrados que justamente o afastavam da atração exteriorizante e sem profundidade simbólica das mercadorias industriais. Por outro lado, aquilo que Benjamin chamava de aura poderia valer também para a atitude esotérica em relação aos objetos, na medida em que os coloca num ponto de 
respeito em relação à sua chegada, sem romper a corrente histórica e iniciática da tradição, através dos tempos, até o momento presente.

Sintetizando, pareceria, à primeira vista, que o esoterismo moderno cresceu num momento paradigmático de nossa civilização: quando o discurso racional da filosofia ameaçou prescindir de vez de um solo transcendente e quando o discurso da ciência ameaçou revelar ou desprezar definitivamente quaisquer dimensões arcanas da realidade, fossem elas físicas ou mentais, pessoas como Blavatsky, Gurdjieff, René Guénon, entre tantos outros, recolocaram as questões dos níveis não-físicos da realidade e de saberes secretos, perdidos no Ocidente (ou congelados nos textos sagrados do seu passado), mas vivos ainda nas tradições espirituais iniciáticas do Oriente. Visto dessa forma, o salto alcançado por obras monumentais como A Doutrina Secreta de Blavatsky, O Arqueômetro de Saint-Yves d'Alveydre, O Ensinamento Secreto de Todas as Épocas, de Manly Hall, entre outras, significou também um salto cultural, preparando o solo para um cosmopolitismo que parece ter vindo para ficar - as tradições religiosas não-ocidentais, sobretudo as asiáticas, ganham cada vez maior visibilidade e já não só no interior dos segmentos intelectualizados do Ocidente.

Como já disse, esse mesmo cosmopolitismo esotérico primeiro influenciou e mais tarde voltou a ser influenciado pela sensibilidade própria da Antropologia. Aqui, enfim, podemos tentar unir os dois contradiscursos ao projeto modernista. No seu ensaio "Modernidade, um projeto inacabado", Habermas resume com mestria o legado da teoria weberiana e explica com didatismo o projeto moderno como sendo o momento da separação das esferas autônomas. Como antropólogos, poderíamos inclusive perceber esse relato no que ele tem de mítico em sua estrutura: o momento pré-moderno, feminino, esotérico, da fusão indiferenciadora, dá lugar ao momento moderno, masculino, exotérico, da separação e do distanciamento discernidor da razão. As várias facetas da atividade humana são então nomeadas com seus atributos de razão: a razão ética, a razão estética e a razão científica só podem ser alcançadas e analisadas a partir do investimento em atos de conhecimento setorizados e sistemáticos.

O que passou então a chamar-se de Ciência Social foi a acomodação disciplinar a essa realidade projetada em um sistema coerente. A Sociologia e a Ciência Política não tiveram dificuldades de adaptar-se ao universo separado dessas esferas. A Antropologia, por outro lado, cuja constituição mesma 
implicou numa pretensão integradora (lembremos da definição clássica e ainda operacionalizável de Edward Tylor: aquele todo complexo...) posiciona-se de um modo enviesado, quando não conflitante, a esse projeto científico modernista. Nenhum campo dos estudos da cultura reflete tão bem essa injunção quanto o da Antropologia da Religião, cujo especialista, se se dispuser a seguir seriamente a agenda acadêmica de cunho modernista, deverá renunciar definitivamente ao ideal de integrar, num gesto único de compreensão, a esfera política com a esfera mística das tradições religiosas. E não esqueçamos o subtítulo do ensaio de Habermas: um projeto inacabado. O que significa dizer que o fosso racional entre as esferas ainda se processa e tende a crescer na medida em que nos tomemos cada vez mais modernos. É essa mesma crítica, com interesses morais e espirituais próprios, que fazem os pensadores esotéricos ao projeto de modernidade - daí se apoiarem, como agenda comum, no que chamam de tradição. Essa tradição é também via de circulação de saber científico, porém de uma ciência que não deseja desvincular-se da moral e da arte. Finalmente, gostaria de adiantar o tema que pretendo desenvolver em um ensaio complementar ao presente. A atitude antropológica guarda bastante similaridade com a atitude esotérica, sobretudo se pensamos num conceito central para a constituição da atitude esotérica moderna: o conceito de tradição. ${ }^{11}$ Por trás dessa palavra está a transmissão viva e direta de um conhecimento arcano e fundamental, que resiste ao trabalho do tempo precisamente por sua capacidade de renovar-se a cada geração, que o encarna em pessoas dotadas da sensibilidade que estamos chamando de esotérica. Entre tantos aspectos desse complexo conceito, a dimensão da oralidade é importante, pois de certa forma toda tradição é, em última instância, oral. E se assim se passam as coisas, a prática etnográfica conduz o antropólogo a deparar-se constantemente com os mestres que transmitem o conhecimento místico e espiritual que circula no seio das tradições religiosas vivas. Essa dimensão da oralidade é feita realidade através da presença, da encarnação do saber lembrado. Esse saber, que deve ser atuado a cada vez que o solicitam, configura exatamente o plano esotérico da vida. E a etnografia do fenômeno religioso, que igualmente só

11 Conceito teorizado exaustivamente pelos esotéricos; ver, a respeito, os ensaios de René Guénon (1932), Seyyed Hossein Nasr (1989), Titus Burckhardt (1979), Ananda Coomaraswami (1991), Frithjuof Schuon (1985) e a exegese comparativa de Antoine Faivre (1994). 
pode ser vivida, é sempre uma imersão numa corrente oral de conhecimento; é, de igual modo, um contato com a presença.

O segundo conceito que nos aproxima da dimensão esotérica é o conceito de adepto, que vem significar aquele iniciado numa determinada tradição esotérica e cujo conhecimento, antes disseminado na qualidade de cultura ou representação coletiva, adquiriu um caráter pessoal, de gnose interiorizada. O que distingue uma Antropologia da Religião é justamente o contato e o reconhecimento da personalidade dos adeptos nas mais diferentes tradições religiosas. O índio mexicano Don Juan, personagem central dos cativantes relatos iniciáticos de Carlos Castañeda; Muchona, grande sacerdote da nação Ndembu da Zâmbia, de quem Victor Tumer construiu um comovedor perfil biográfico; Ogotemmêli, o sábio e filósofo Dogon, sobre quem Marcel Griaule escreveu um livro inteiro e que Victor Turner chegou a comparar com o místico teósofo Jacob Boehme; os vários xamãs aborígenes australianos que ensinaram a Elkin como penetrar na dimensão espiritual conhecida como Dreamtime (tempo do sonho); Black Elk (Alce Negro), sacerdote Sioux, que em 1931 ditou para John Neihardt a última grande visão cósmica dos índios das planícies norte-americanas; Adamu Jenitongo, velho sábio dos Songhay do Niger, que iniciou Paul Stoller na sua tradição de conhecimento mágico. ${ }^{12}$ Todas essas pessoas dotadas de uma espiritualidade excepcional, expoentes de culturas religiosas muito distintas, encarnam o ideal antropológico de ir "em busca do milagroso", para utilizar a imagem de Ouspensky; de rebelar-se contra a medida niveladora da razão embutida no projeto da modernidade. É possível, enfim, conceber a Antropologia como uma tentativa de testar o que Frithjof Schuon chama da “unidade transcendente das religiões”, percorrendo caminhos simbólicos que complementem as análises praticadas pelos seguidores da tradição, em geral mais presos às correntes letradas do espectro da mística universal. Filhas ambas, assim, do projeto moderno, tanto as tradições esotéricas como a Antropologia são partes de uma ciência sagrada muito mais ampla, que se recusa a fragmentar o olhar ao tentar desvendar as complexidades das relações do homem consigo mesmo, com o outro e com o universo.

12 Para os perfis biográficos desses expoentes do esoterismo extra-ocidental, ver as obras de Victor Turner (1976), Marcel Griaule (1965), A. P. Elkin (1977), John Neihardt (1972) e Paul Stoller (1989); ver também o dossiê de Richard De Mille (1990) sobre a controvérsia causada no meio académico pelos relatos de Carlos Castañeda. 


\section{Referências*}

AMALADOSS, M. Towards fullness: searching for an integral spirituality. Bangalore: Catechetical and Liturgical Centre, 1994.

BLAVATSKY, H. P. Isis unveiled. Adyar: The Theosophical Publishing House, 1972. $2 \mathrm{v}$.

BLAVATSKY, H. P. The secret doctrine. Adyar: The Theosophical Publishing House, 1979. 3 v.

BURCKHARDT, T. Principes et méthodes de l'art sacrée. Lyon, 1958.

BURCKHARDT, T. Ciencia moderna y sabiduría tradicional. Madrid: Taurus, 1979.

CARVALHO, J. J. de. A antropologia e o niilismo filosófico contemporâneo. Anuário Antropológico '86, Brasília: Editora UnB: Tempo Brasileiro, p. 153181, 1988.

CARVALHO, J. J. de. Características do fenômeno religioso na sociedade contemporânea. In: BINGEMER, M. C. (Org.). O impacto da modernidade sobre a religião. São Paulo: Loyola, 1992. p. 133-195.

CARVALHO, J. J. de. Antropologia: saber acadêmico e experiência iniciática. Anuário Antropológico/90, Rio de Janeiro: Tempo Brasileiro, p. 91-107, 1993.

CARVALHO, J. J. de. O encontro de velhas e novas religiões. In: MOREIRA, A.; ZICMAN, R. (Org.). Misticismo e novas religiões. Petrópolis: Vozes: USF-IFAN, 1994a. p. 67-98.

\footnotetext{
Uma nota sobre esta bibliografia. Dada a escassez de estudos sistemáticos sobre as tradições esotéricas, escritos em língua portuguesa, decidi apresentar uma seleção bibliográfica que poderá servir também de guia básico de estudos. Acredito que um mergulho nas obras aqui indicadas poderá permitir ao leitor uma entrada bastante segura no campo intelectual e espiritual das tradições esotéricas ocidentais.
} 
CARVALHO, J. J. de. Tendências religiosas no Brasil contemporâneo. In: A IGREJA CATÓLICA DIANTE DO PLURALISMO RELIGIOSO NO BRASIL (III). São Paulo: Paulus, 1994b. p. 21-36. (Col. Estudos da CNBB, vol. 71).

CARVALHO, J. J. de. Mutus Liber: o livro mudo da alquimia. São Paulo: Attar, 1995.

CARVALHO, J. J. de. A tradição mística afro-brasileira. Religião e Sociedade, v. 18, n. 2, p. 93-122, 1997.

COOMARASWAMI, A. Sobre la doctrina tradicional del arte. Barcelona: Ediciones de la Tradición Unánime, 1983.

COOMARASWAMI, A. O que é civilização. São Paulo: Livrarias Siciliano, 1991.

COPENHAVER, B. Hermetica. Cambridge: Cambridge University Press, 1992.

D'ALVEYDRE, S.-Y. El Arqueómetro: clave de todas las religiones y de todas las ciencias de la Antigüedad. Madrid: Luís Cárcamo Editor, 1981.

DE MILLE, R. The Don Juan papers. Belmont: Wadsworth Publishing, 1990.

DOBBS, B. J. The foundations of Newton's alchemy. Cambridge: Cambridge University Press, 1975.

ELIADE, M. O oculto e o mundo moderno. In: ELIADE, M. Ocultismo, bruxaria e correntes culturais. Belo Horizonte: Interlivros, 1979.

ELKIN, E. P. Aboriginal men of high degree. New York: St. Martins’ Press, 1977.

EVOLA, J. A revolta contra o mundo moderno. Lisboa: Publicações Dom Quixote, 1989.

FAIVRE, A. Access to western esotericism. New York: State University of New York Press, 1994. 
FAIVRE, A.; NEEDLEMAN, J. (Ed.). Modern esoteric spirituality. New York: Crossword, 1995.

FULCANELLI, O. Mistério das catedrais. Lisboa: Edições Setenta, 1975.

FULCANELLI, O. As mansões filosofais. Lisboa: Edições Setenta, 1977.

GAUCHET, M. Le dêsenchantement du monde. Paris: Gallimard, 1985.

GRIAULE, M. Conversations with Ogotemmêli. London, 1965.

GUÉNON, R. Introduction générale a l'étude de las doctrines hindoues. Paris: Les Éditions Vega, 1932.

GUÉNON, R. Símbolos fundamentales de la ciencia sagrada. Buenos Aires: EUDEBA, 1969.

GUÉNON, R. A crise do mundo moderno. Lisboa: Editorial Vega, 1977.

GUÉNON, R. O reino da quantidade e os sinais dos tempos. Lisboa: Publicações Dom Quixote, 1989.

GURDJIEFF, G. I. Viewsfom the real world. New York: E. P. Dutton, 1973.

HABERMAS, J. Modernity - an incomplete project. In: FOSTER, H. (Ed.). The anti-aesthetic: essays on postmodern culture. Seattle: Bay Press, 1983.

HALL, M. P. Kabbalistes chrêtiens. Paris: Albin Michel, 1979. (Col. Cahiers de l'Hermétisme).

HALL, M. P. The secret teachings of all ages: being an interpretation of the secret teachings concealed within the rituais, allegories and mysteries of all ages. Los Angeles: The Philosophical Research Society, 1988.

JUNG, C. G. Memórias, sonhos, reflexões. Rio de Janeiro: Nova Fronteira, 1990.

NASR, S. H. Knowledge and the sacred. New York: State University of New York Press, 1989. 
NASR, S. H. Islamic art and spirituality. New York: State University of New York Press, 1992.

NEEDLEMAN, J. Cristianismo perdido: uma viagem de redescoberta. São Paulo: Martins Fontes, 1987.

NEIHARDT, J. Black Elk speaks. New York: Pocket Book, 1972.

NICOLL, M. Psychological commentaries on the teaching of G. I. Gurdjieff. London:Vincent Stewart, 1957.

OUSPENSKY, P. D. A new model of the universe. New York: Alfred A. Knopf, 1967.

PANIKKAR, R. The intrareligious dialogue. New York: Paulist Press, 1978.

PANOFSKY, E. Gothic architecture and scholasticism. New York: Meridian Book, 1976.

PIPER, J. El ocio y la vida intelectual. Madrid: Ediciones Rialp, 1983.

PIPER, J. Présence d’Hermés Trismégiste. Paris: Albin Michel, 1988. (Col. Cahiers de l'Hermétisme).

SAUNIER, J. A Sinarquia, ou o velho sonho de uma sociedade nova. Lisboa: Edições 70, 1979.

SCHUON, F. Tras las huellas de la religión perenne. Barcelona: José J. de Olaneta, 1982.

SCHUON, F. O esoterismo como princípio e como caminho. São Paulo: Pensamento, 1985.

SCHUON, F. A unidade transcendente das religiões. Lisboa: Publicações Dom Quixote, 1991.

STEINER, G. Heidegger. Hassocks: The Harvester Press, 1978.

STOLLER, P. The taste of ethnographic things. Philadelphia: University of Pennsylvania Press, 1989. 
STOLLER, P.; OLKES, C. In sorcery's shadow. Chicago: The University of Chicago Press, 1987.

TIRYAKIAN, E. Toward the sociology of esoteric culture. In: TIRYAKIAN, E. (Ed.). On the margin of the visible. New York: John Wiley \& Sons, 1974.

TURNER, V. Muchona the homet. In: TURNER, V. The forest of symbols. Ithaca: Comell University Press, 1976.

VAZ, H. de L. Cultura e religião. In: VAZ, H. de L. Escritos de filosofia: vol. 2. São Paulo: Loyola, 1988.

VAZ, H. de L. Religião e modernidade filosófica. In: BINGEMER, M. C. (Org.). O impacto da modernidade sobre a religião. São Paulo: Loyola, 1992. 